Supplement of Ocean Sci., 10, 907-921, 2014

http://www.ocean-sci.net/10/907/2014/

doi:10.5194/os-10-907-2014-supplement

(C) Author(s) 2014. CC Attribution 3.0 License.

(c) (i)

Supplement of

\title{
On the glacial and interglacial thermohaline circulation and the associated transports of heat and freshwater
}

M. Ballarotta et al.

Correspondence to: M. Ballarotta (maxime.ballarotta@natgeo.su.se) 
This supplementary material includes the Figures S1 to S5. Figure S1 presents a comparison of the Last Glacial Maximum (LGM) and the Present-Day (PD) time and zonally averaged atmospheric forcing used in our experiments. Figure S2 shows the temperature and salinity drifts at the end of the LGM and PD simulations. Figure S3 supplements the figure 2. It represents the time and zonally averaged temperature in the Atlantic and Pacific Oceans. The meridional circulations are superimposed. Figure S4 supplements figure 8 and 10. It represents the LGM and PD volumetric density in the Salinity-Temperature diagram for the Atlantic and Pacific Oceans. Finally Figure S5 shows the surface water fluxes for the LGM and the PD simulations. 

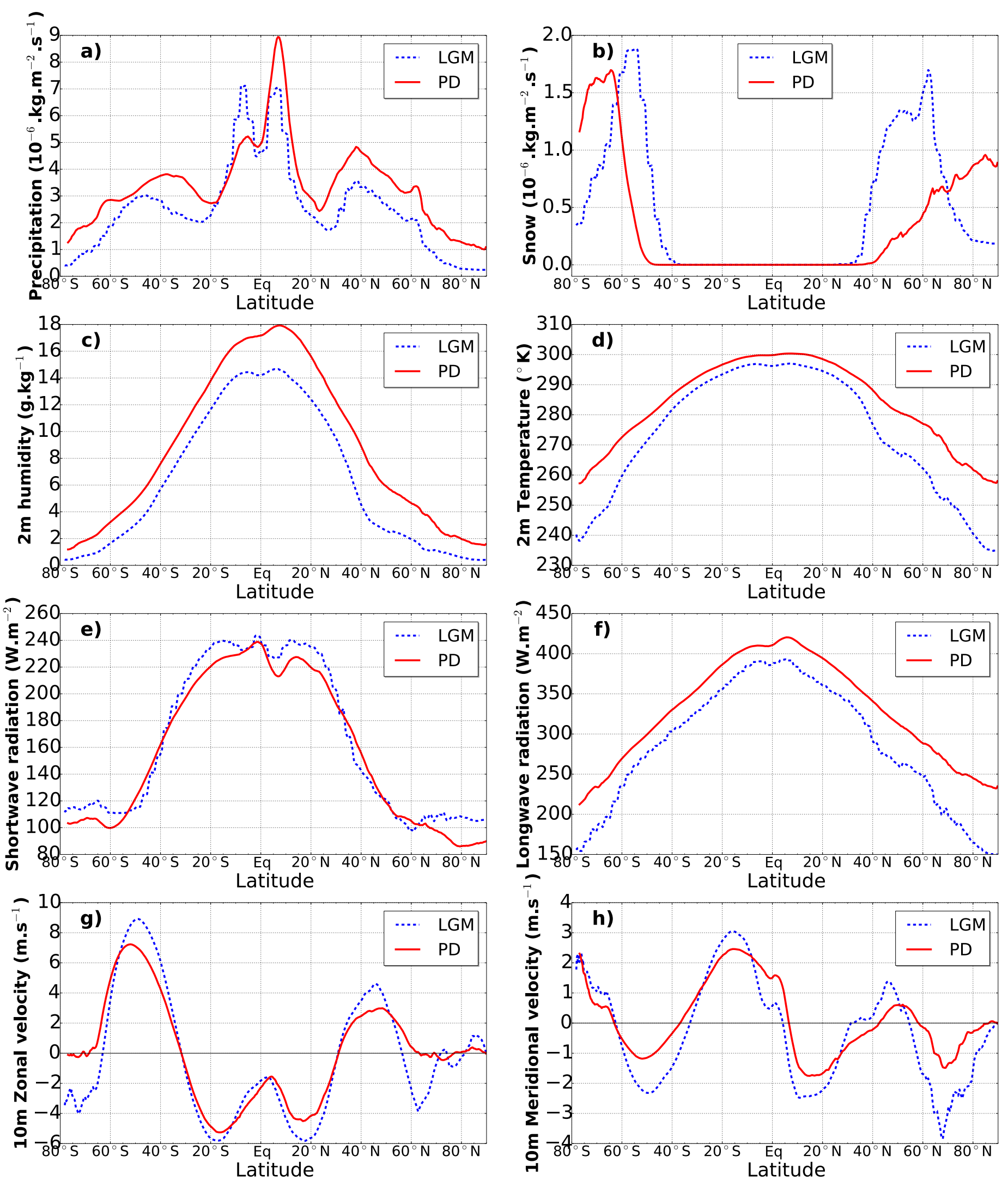

Fig. S1. Time and zonally averaged atmospheric forcing in the LGM and PD experiment. 

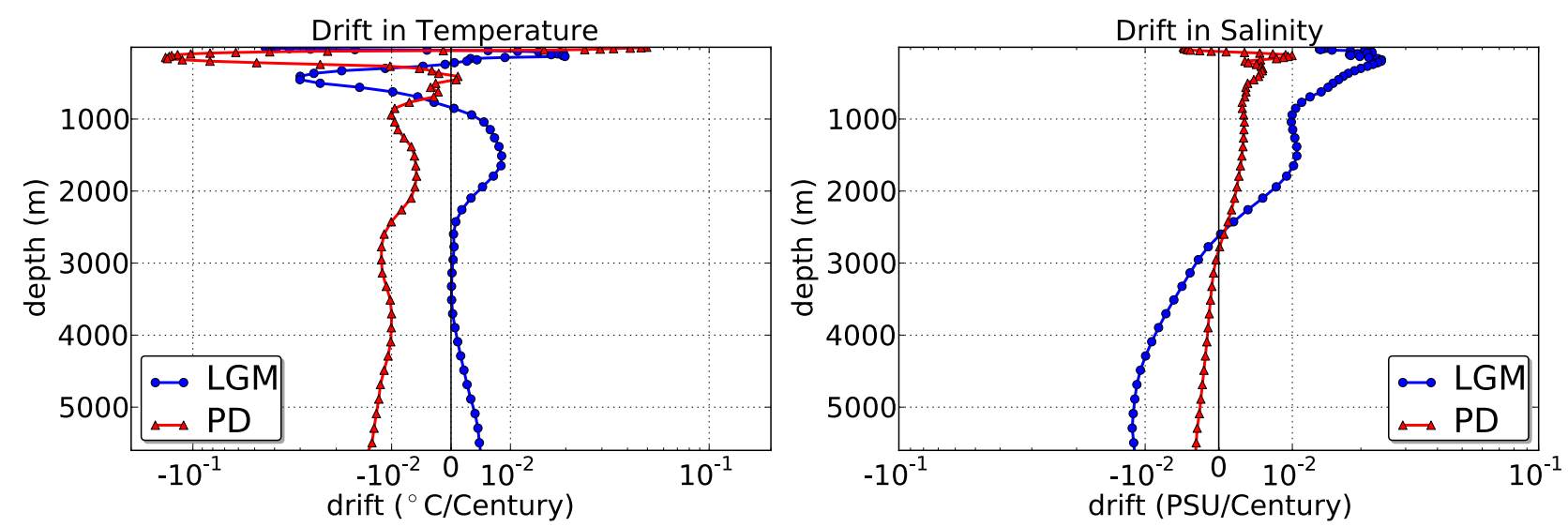

Fig. S2. Globally averaged temperature and salinity trends in final stage of the LGM and PD simulations
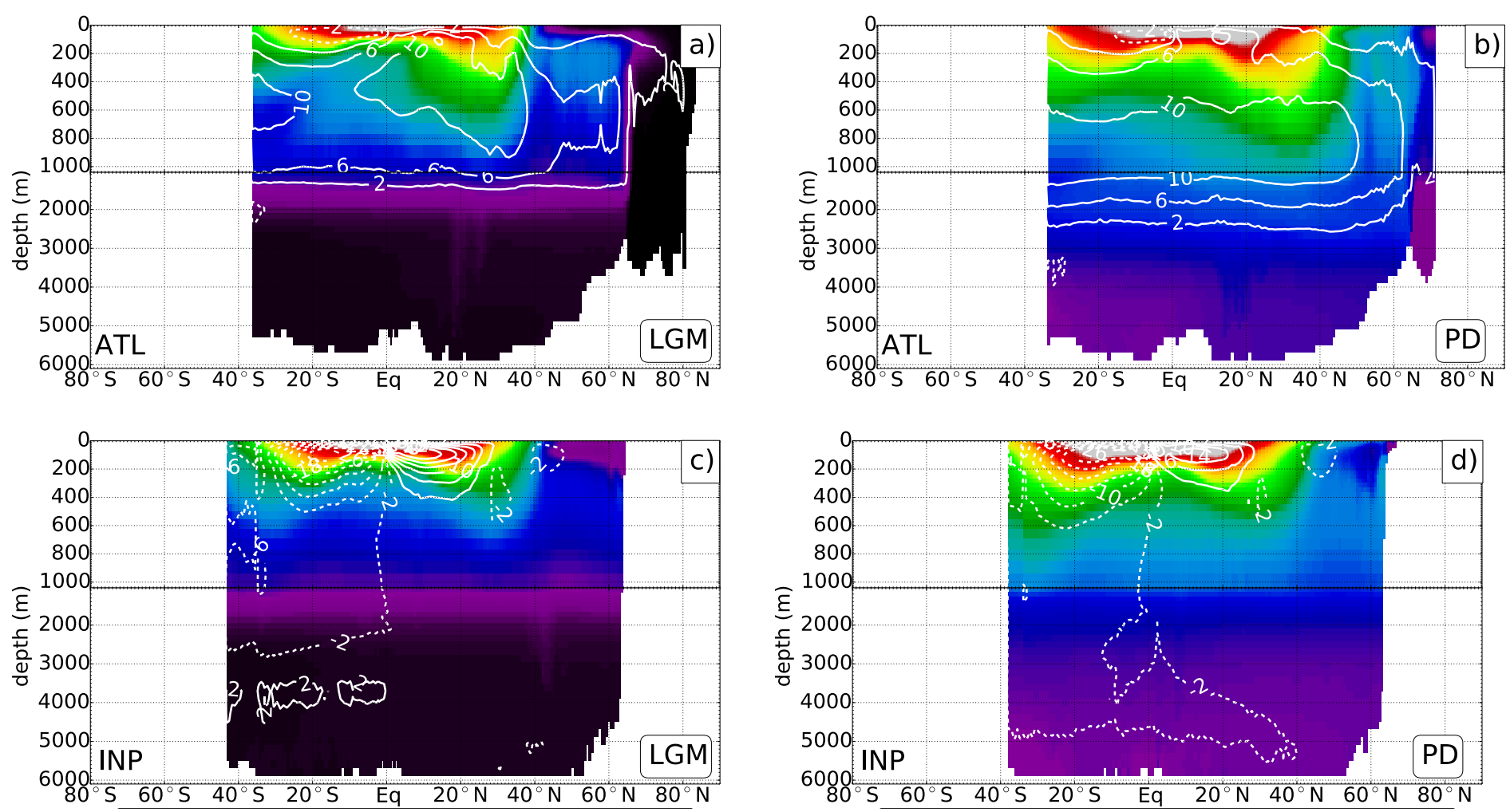

Fig. S3. LGM and PD meridional overturning circulation in latitude-depth coordinates superimposed on the time-zonally averaged temperature a),b) in the Atlantic basin and c),d) the Indo-Pacific basin. The contour interval for the circulation is $2 \mathrm{~Sv}$. Thick lines correspond to clockwise circulations whereas dashed lines are for counter-clockwise motions. 

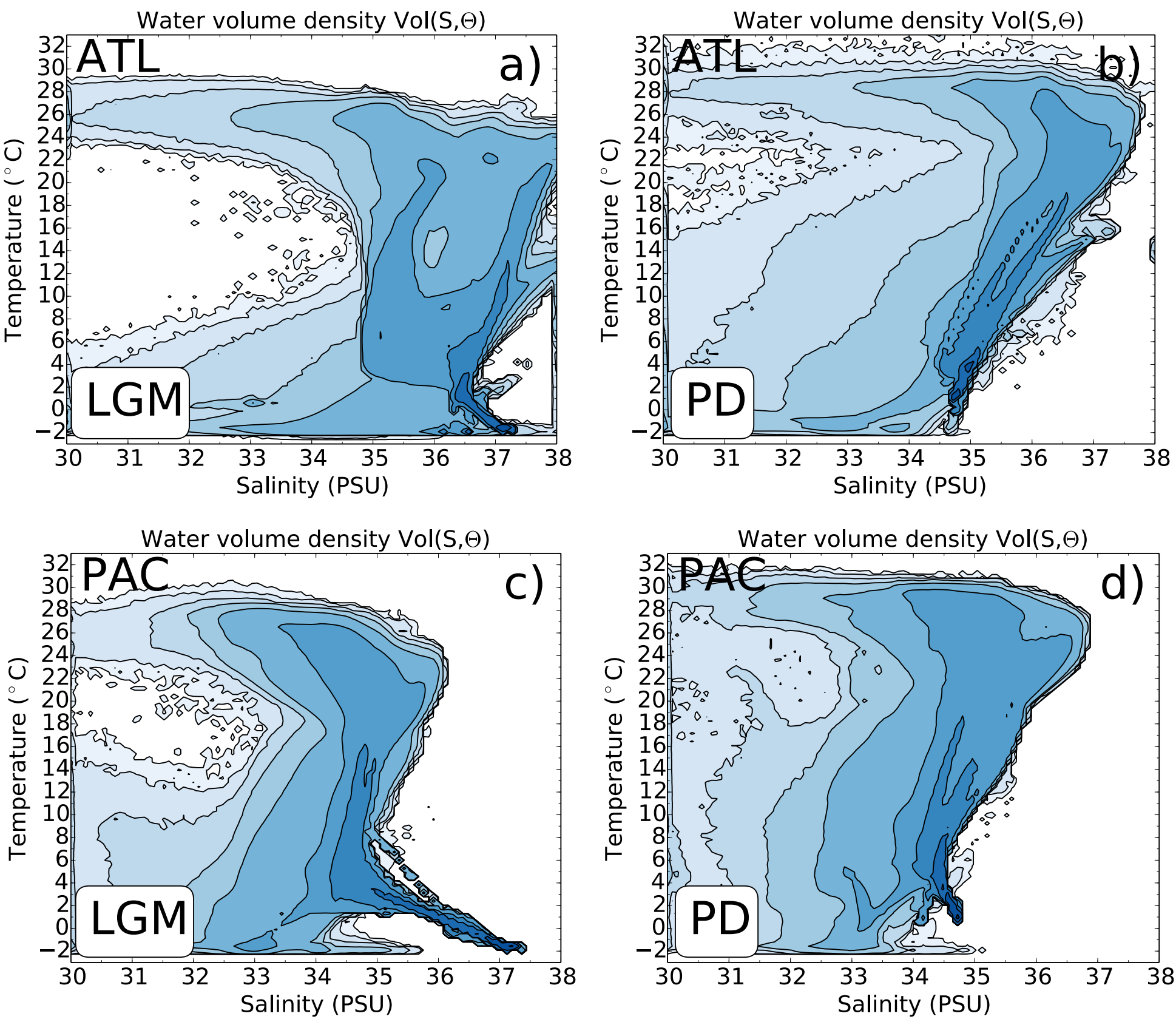

$$
\begin{array}{cccccc}
\hline 0^{2} & 10^{4} & 10^{6} & 10^{8} & 10^{10} & 10^{12} \\
& & 10^{6} \mathrm{~m}^{3}\left({ }^{\circ} \mathrm{C} . \text { PSU }\right)^{-1} & &
\end{array}
$$

Fig. S4. LGM and PD sea-water volume density distribution projected in the temperature-salinity diagram for a),b) the atlantic basin, c),d) the Pacific basin. The contour interval for the volume density is $10^{6} \mathrm{~m}^{3} .\left({ }^{\circ} \mathrm{C} . \mathrm{PSU}\right)^{-1}$. The volume density at $\mathrm{S}=30 \mathrm{PSU}$ and $\mathrm{S}=38 \mathrm{PSU}$ includes volume density of water with $S \leq 30 \mathrm{PSU}$ and $\mathrm{S} \geq 38 \mathrm{PSU}$, respectively 

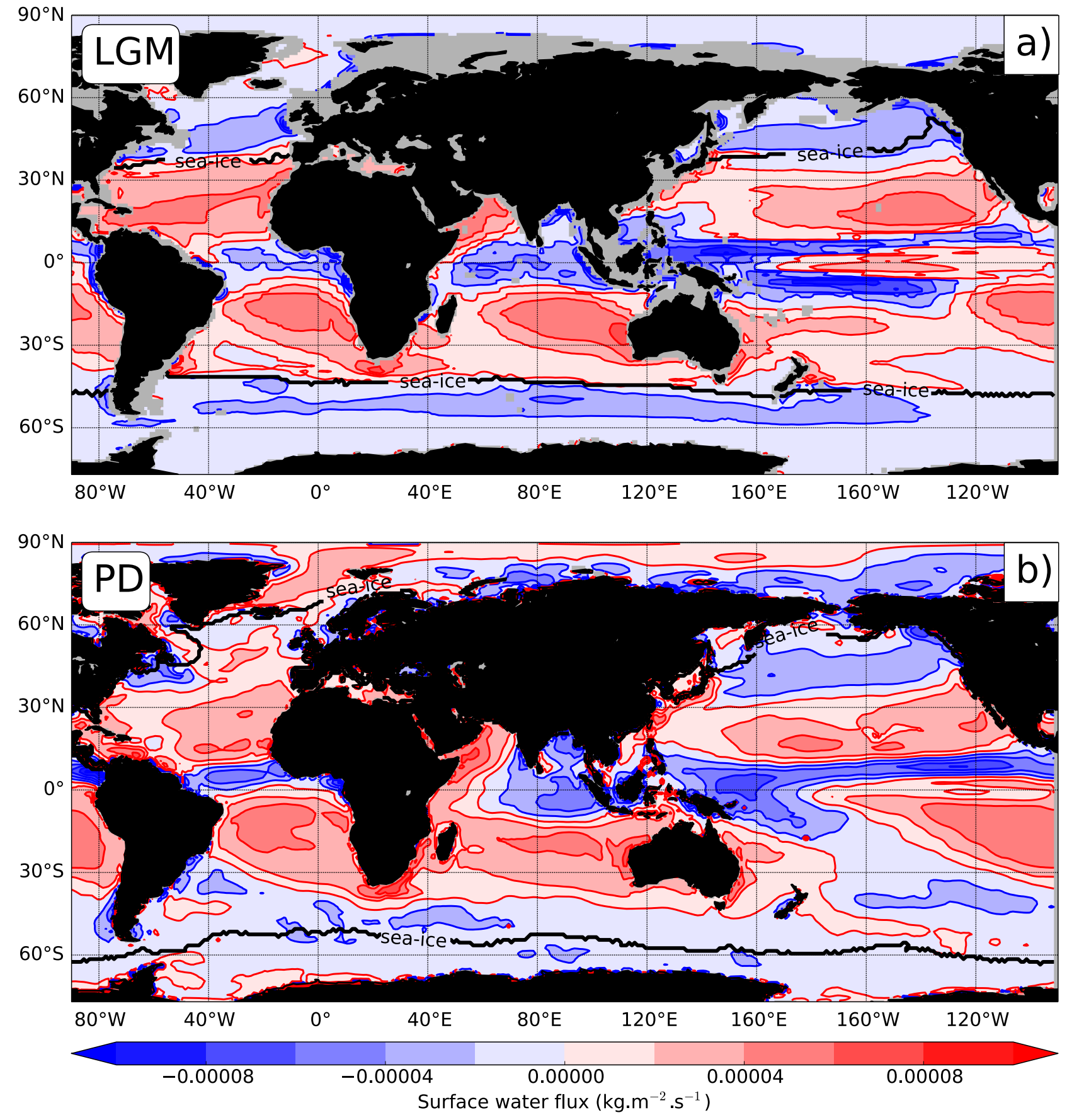

Fig. S5. Time averaged surface water flux in a) the LGM simulation and b) the PD simulation. Positive values are upward fluxes, and negative value downward fluxes. Unit in $\mathrm{kg} \cdot \mathrm{m}^{-2} \cdot \mathrm{s}^{-1}$. 